Article

\title{
Significant Influence of a Single Atom Change in Auxiliary Acceptor on Photovoltaic Properties of Porphyrin-Based Dye-Sensitized Solar Cells
}

\author{
Haoran Zhou, Jung-Min Ji, Min Su Kim and Hwan Kyu Kim *D \\ Global GET-Future Laboratory \& Department of Advanced Materials Chemistry, Korea University, \\ 2511 Sejong-ro, Sejong 339-700, Korea; zhouhaoran@naver.com (H.Z.); manbbong@korea.ac.kr (J.-M.J.); \\ kimms38@korea.ac.kr (M.S.K.) \\ * Correspondence: hkk777@korea.ac.kr; Tel.: +82-44-860-1493
}

Received: 19 November 2018; Accepted: 7 December 2018; Published: 11 December 2018

\begin{abstract}
The rational design of porphyrin sensitizers is always crucial for dye-sensitized solar cells (DSSCs), since the change of only a single atom can have a significant influence on the photovoltaic performance. We incorporated the pyridothiadiazole group, as a stronger electron-withdrawing group, into the commonly well-established skeleton of D-porphyrin-triple bond-acceptor sensitizers by a single atom change for a well-known strong electron-withdrawing benzothiadiazole (BTD) unit as an auxiliary acceptor. The impact of the pyridothiadiazole group on the optical; electrochemical; and photovoltaic properties of D- $\pi-A$ porphyrin sensitizers was investigated with comparison for a benzothiadiazole-substituted SGT-020 porphyrin. The pyridothiadiazole-substituted SGT-024 porphyrin dye was red-shifted so that the absorption range might be expected to achieve higher light harvest efficiency (LHE) than the SGT-020 porphyrin. However, all the devices were fabricated by utilizing SGT-020 and SGT-024, evaluated and found to achieve a cell efficiency of $10.3 \%$ for SGT-020-based DSSC but $4.2 \%$ for SGT-024-based DSSC under standard global AM 1.5G solar light conditions. The main reason is the lower charge collection efficiency of SGT-024-based DSSC than SGT-020-based DSSC, which can be attributed to the tilted dye adsorption mode on the $\mathrm{TiO}_{2}$ photoanode. This may allow for faster charge recombination, which eventually leads to lower $J_{s c}$, $V_{o c}$ and power conversion efficiency (PCE).
\end{abstract}

Keywords: $\mathrm{D}-\pi-\mathrm{A}$ structural porphyrin; acceptor units; dye-sensitized solar cells; charge recombination; charge collection efficiency

\section{Introduction}

A huge amount of work has recently concentrated on third-generation solar cell technology development with low cost as emerging photovoltaics, such as dye-sensitized solar cells (DSSCs) [1,2], organic photovoltaics (OPVs) [3-5], perovskite solar cells (PSCs) [6-8], etc. Among the various solar technologies, DSSCs have garnered considerable attention due to the simple fabrication process, low cost, low toxicity, and high PCE under ambient lighting conditions [9,10]. In 1991 Grätzel and $\mathrm{O}^{\prime}$ Regan first introduced mesoporous $\mathrm{TiO}_{2}$ nanocrystal layers into the DSSC system [11]. This led to a substantial improvement in photoelectric transformation efficiency. Since then, over the past 28 years, DSSCs have continued to show improved PCE [12-14]. Until now, state-of-the-art DSSCs have achieved PCEs approaching $>11.9 \%$ for ruthenium complexes [15], $>14 \%$ for metal-free D- $\pi-\mathrm{A}$ structural organic sensitizers [16], and $14.64 \%$ for D- $\pi-A$ structural organic sensitizer-based tandem DSSCs under standard (1.5) illumination [13]. In comparison with ruthenium sensitizers $[17,18]$ and metal-free sensitizers $[19,20], \mathrm{D}-\pi-\mathrm{A}$ structural porphyrin sensitizers [21-23] have been attractive 
due to their extremely high molar extinction coefficient, exceptional ability to harvest light, and high photostability. To date, porphyrin-based DSSCs have achieved PCE by more than $13 \%$ under standard (1.5) illumination [24,25].

However, there are also some drawbacks due to the nature of porphyrins, such as the weak absorption in the range of 500-600 nm, the lack of absorption in the near-infrared region (NIR), and the dye aggregation caused by the extended $\pi$-conjugation structure [26-30]. It is apparent that these problems could be overcome by rational structural optimization. For example, long and well-adjusted alkoxy chains were introduced to porphyrin molecules, which significantly diminished the dye aggregation and reduced the interface back electron transfer rate [31]. The introduction of a benzothiadiazole (BTD) unit in the acceptor part to the well-established platform of D-porphyrin-triple bond-acceptor sensitizers was also a promising approach for elevating light-harvesting properties, as well as the photovoltaic performance. Up to now, the BTD unit was one of the most commonly used auxiliary electron acceptors in the well-known skeleton of D-porphyrin-triple bond-BTD-acceptor sensitizers for DSSCs [32-34].

In order to reduce the HOMO (highest occupied molecular orbital)-LUMO (lowest unoccupied molecular orbital) energy gap as well as extend the absorption range, a boosted electron-withdrawing pyridothiadiazole unit was introduced into the well-established platform of D-porphyrin-triple bond-BTD-acceptor sensitizers by a single atom change for the well-known strong electron-withdrawing benzothiadiazole (BTD) unit as an auxiliary acceptor. Although the pyridothiadiazole unit has been widely used in D-A polymers in OPVs $[35,36]$ and metal-free organic sensitized solar cells $[37,38]$, no application of the pyridothiadiazole unit has been explored in porphyrin-sensitized solar cells. Thus, based on our previously reported dye of SGT-020 [25], we expected that the pyridothiadiazole unit in $\mathrm{D}-\pi-\mathrm{A}$ porphyrin sensitizers could improve the absorption ability in NIR as well as the light harvest efficiency. Thus, a novel D- $\pi-\mathrm{A}$ structural porphyrin sensitizer was designed and synthesized, named as SGT-024, as shown in Scheme 1. Meanwhile, the optical properties, electrochemical properties, and photovoltaic performances were systemically investigated.
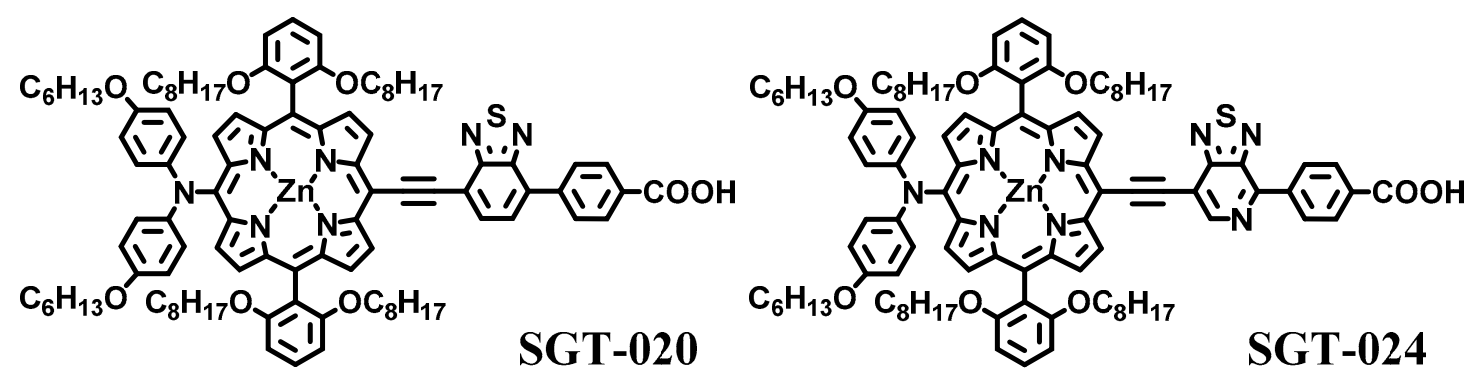

Scheme 1. Molecular structures of SGT-020 and SGT-024 sensitizers.

\section{Synthetic Procedure}

All reagents were purchased from Alfa Aesar (Haverhill, MA, USA ), TCI (Tokyo, Japan), and Sigma-Aldrich (St. Louis, MO, USA) unless stated otherwise. The synthesis routes of SGT-024 were shown in Scheme 2, and compound 1 [37], compound 3 [25], and SGT-020 [25] were synthesized according to the respective literature procedures. Details on the synthetic procedure, instrumentation, DSSC fabrication, photovoltaic parameters, ${ }^{1} \mathrm{H}-\mathrm{NMR},{ }^{13} \mathrm{C}-\mathrm{NMR}$, and MALDI-TOF data are given in the Supplementary Materials. 


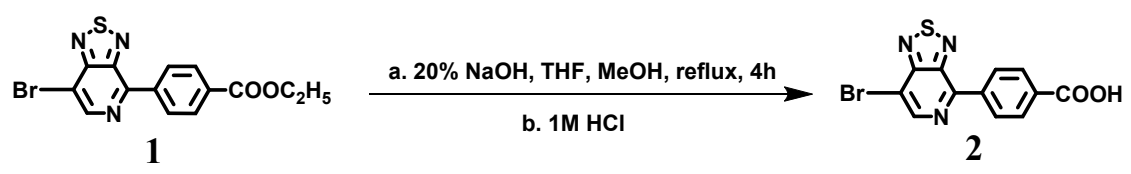

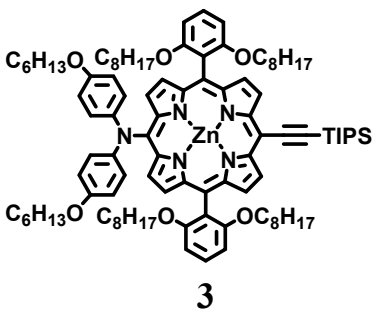

3 a. TBAF ,THF, $0.5 \mathrm{~h}$, r.t

b. Pd2(dba)3 AsPh3 Et3N, THF, reflux, 5h

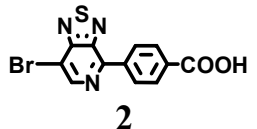

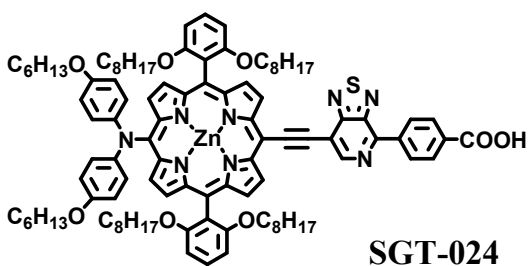

SGT-024

Scheme 2. Synthesis routes of SGT-024.

\section{Results and Discussion}

The UV-visible spectra of the dyes SGT-020 and SGT-024 in THF were collected and reported in Figure 1. It is obvious that SGT-020 and SGT-024 showed two intense absorption regions within the ranges of 400 to $500 \mathrm{~nm}$ (Soret band) and 600 to $800 \mathrm{~nm}$ (Q band). In Table 1, compared with the molar extinction coefficient $(\varepsilon)$ of $143,040 \mathrm{M}^{-1} \mathrm{~cm}^{-1}$ at the maximum absorption wavelength $\left(\lambda_{\max }=454 \mathrm{~nm}\right)$ observed for SGT-020, the $\lambda_{\text {max }}$ of SGT-024 is $430 \mathrm{~nm}$ with a coefficient of $123,162 \mathrm{M}^{-1} \mathrm{~cm}^{-1}$. It should be noted that the Soret band peaks of SGT-024 were blue-shifted but the Q bands were significantly red-shifted when a pyridothiadiazole unit was introduced into the platform of D-porphyrin-triple bond-acceptor sensitizers by a single atom change for the well-known strong electron-withdrawing benzothiadiazole (BTD) unit. Furthermore, the fluorescent emission spectra were also measured in THF, as shown in Figure 1. SGT-020 and SGT-024 exhibited major emission bands at 724 and 791 nm, respectively. Therefore, the optical properties of these two porphyrin sensitizers revealed that the light capture region could be expanded by introducing the stronger electron-withdrawing moiety of the pyridothiadiazole unit.

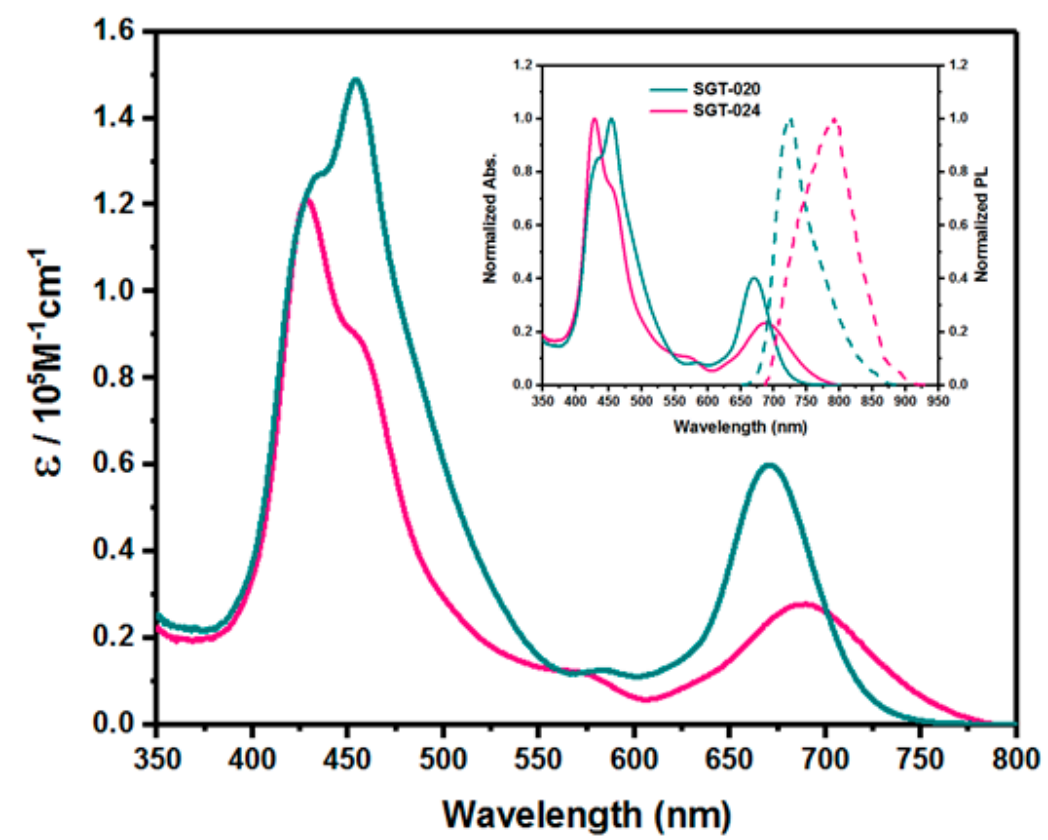

Figure 1. Absorption spectra and emission spectra of SGT-020 and SGT-024 in THF. 
The electrochemical properties of SGT-020 and SGT-024 were evaluated in THF with $0.1 \mathrm{M}$ $\mathrm{TBAPF}_{6}$ as an electrolyte, using cyclic voltammetry (CV) (see Figure S2); the corresponding data are collected in Table 1. As shown in Figure 2, due to the fact that they have the same donor unit, their ground state oxidation potentials, which correspond to the HOMO energy levels of SGT-020 and SGT-024, are nearly the same. Meanwhile, from the HOMO-LUMO band gap and the oxidation potential, the reduction potentials of SGT-020 and SGT-024 were determined to be -0.93 and $-0.81 \mathrm{eV}$, respectively. This difference in reduction potentials could be ascribed to the structural changes in the acceptor group. The results also revealed that the reduction potential values are much more negative than the conducting band $(\mathrm{CB})$ of $\mathrm{TiO}_{2}$ and the oxidation potential values are much more positive than the $\mathrm{Co}(\mathrm{bpy}) 3^{2+/ 3+}$ (bpy $=2,2^{\prime}$-bipyridine) redox couple $(0.56 \mathrm{~V}$ vs. NHE), indicating that all of the electron transfer processes for two porphyrin sensitizers should occur efficiently due to the sufficient driving force.

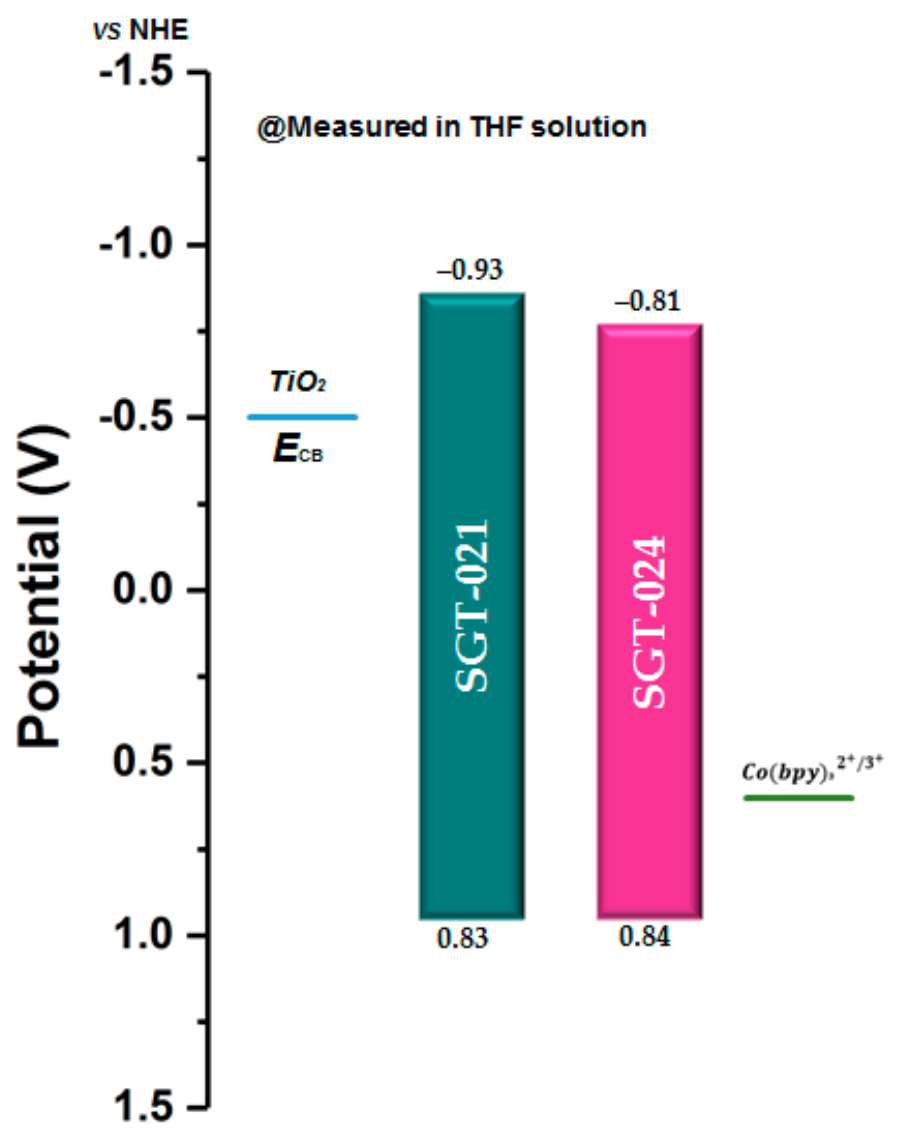

Figure 2. Energy-level diagram of SGT-020 and SGT-024.

Table 1. Photophysical and electrochemical data for SGT-020 and SGT-024.

\begin{tabular}{|c|c|c|c|c|c|c|}
\hline Dye & $\lambda_{\text {abs max }}{ }^{a}(\mathrm{~nm})$ & $\mathcal{\varepsilon}\left(\mathrm{M}^{-1} \mathrm{~cm}^{-1}\right)$ & $\lambda_{\mathrm{em} \max }{ }^{\mathrm{a}}(\mathrm{nm})$ & $E_{0-0}^{b}(\mathrm{eV})$ & $\begin{array}{l}S^{+} / S^{\mathrm{c}}(\mathrm{eV}) \\
{[\mathrm{V} \text { vs. NHE] }}\end{array}$ & $\begin{array}{l}S^{+} / S^{* \mathrm{~d}}(\mathrm{eV}) \\
{[\mathrm{V} \text { vs. NHE] }}\end{array}$ \\
\hline SGT-020 & $\begin{array}{c}454 \\
670\end{array}$ & $\begin{array}{r}143,040 \\
59,916\end{array}$ & 724 & 1.73 & 0.83 & -0.93 \\
\hline SGT-024 & $\begin{array}{c}430 \\
687\end{array}$ & $\begin{array}{c}123,162 \\
27790\end{array}$ & 791 & 1.65 & 0.84 & -0.81 \\
\hline
\end{tabular}

${ }^{a}$ Absorption and emission spectra were measured in THF. ${ }^{b} E_{0-0}$ was determined from the intersection of normalized absorption and emission spectra in THF. ${ }^{c}$ Oxidation potentials of dyes were measured in THF with $0.1 \mathrm{M}$ $\mathrm{TBAPF}_{6}$, ferrocene/ferrocenium internal reference. ${ }^{\mathrm{d}}$ Excited-state oxidation potentials were calculated according to $\left(S^{+} / S^{\mathrm{c}}\right)-E_{0-0}$ 
DFT calculations at the M06 [39]/6-31G [40] (LANL2DZ [41] for Zn atom) level were carried out to better understand the electron distribution and the molecular geometries. The optimized ground state molecular structures and dihedral angles (between BTD/pyridothiadiazole unit and benzoic acid) of two porphyrins are shown in Figure 3 and Table S1. The electron distribution of the HOMO energy levels was mainly delocalized at the diphenylamine donor unit and porphyrin core. However, as for the electron distribution of the LUMO energy levels, SGT-024 showed a more evident shift to the unit of benzoic acid than SGT-020. Thus, SGT-024 was expected to show enhanced intramolecular charge transfer (ICT) compared to that of SGT-020. Furthermore, in the optimized structures of SGT-020 and SGT-024, the dihedral angles between the adjacent auxiliary acceptor and benzoic acid are $35.02^{\circ}$ and $16.06^{\circ}$, respectively. Therefore, owing to the significant reduction of the torsion angle, SGT-024 displayed more efficient $\pi$-conjugation and a better coplanar geometry in comparison with SGT-020, but this geometry would increase the possibility of dye aggregation.

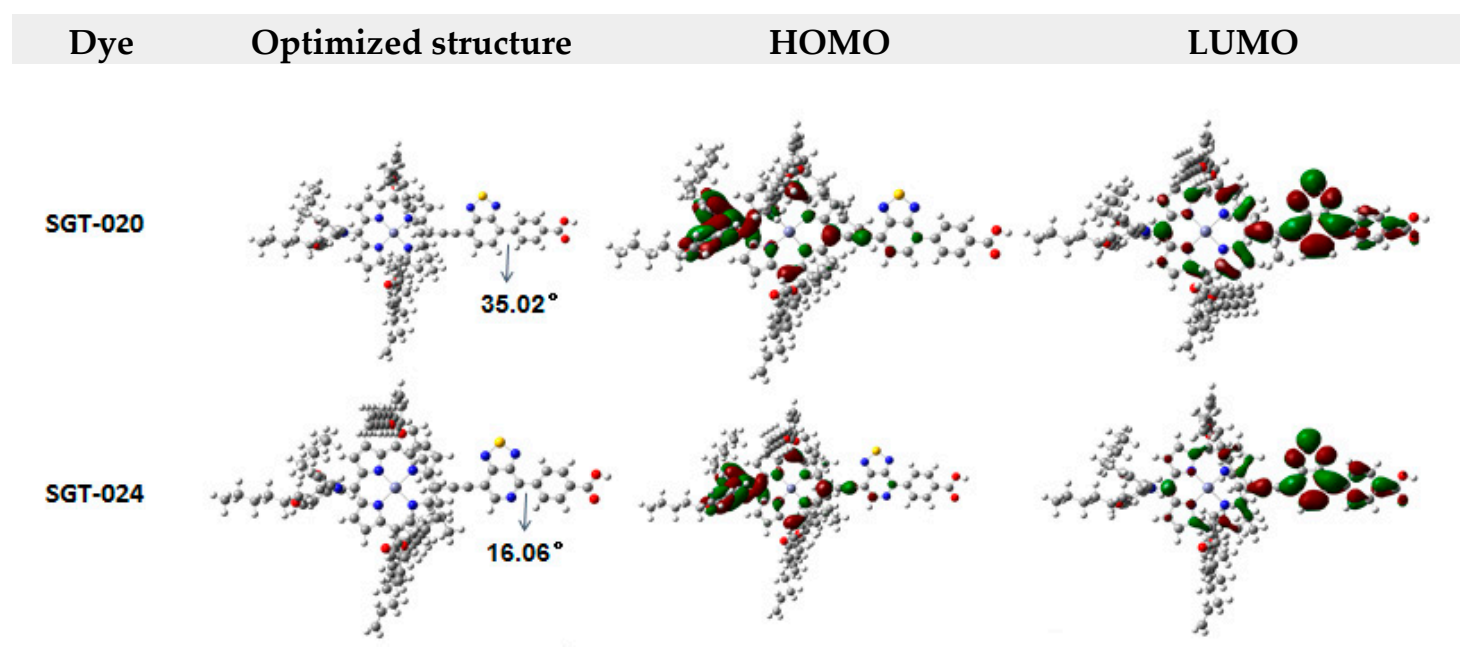

Figure 3. Optimized molecular geometries and electron distributions of the HOMO and LUMO energy levels of SGT-020 and SGT-024.

The photovoltaic characteristics of the SGT-020- and SGT-024-based devices were measured under standard AM 1.5 conditions. The porphyrin-based $\mathrm{TiO}_{2}$ films were used as the photoanode in DSSCs, employing the $\mathrm{Co}(\mathrm{bpy})_{3}{ }^{2+/ 3+}$ redox couple as electrolyte and CDCA (chenodeoxycholic acid) as co-adsorbent. The relevant photocurrent density-voltage (J-V) curves are shown in Figure 4a and the device parameters are summarized in Table 2. As compared to the reference dye SGT-020 $\left(J_{\mathrm{sc}}=14.8 \mathrm{~mA} \mathrm{~cm}^{-2}, V_{\mathrm{oc}}=0.806 \mathrm{~V}, \mathrm{FF}=73.2 \%\right.$ and $\left.\mathrm{PCE}=8.7 \%\right)$, the pyridothiadiazole-incorporated dye SGT-024 only showed a moderate PCE of only 1.7\%. The $J_{\text {sc }}$ value of SGT-024 dramatically dropped to $3.3 \mathrm{~mA} \mathrm{~cm}^{-2}$ and its $V_{\text {oc }}$ also decreased to $0.655 \mathrm{~V}$. To further investigate the $J_{S c}$ value of each porphyrin sensitizer, the corresponding IPCE (incident photon-to-electron conversion efficiency) spectra of SGT-020 and SGT-024-based devices were measured under AM 1.5G solar light. As shown in Figure 4b, SGT-024 sensitizers exhibited a broader, weaker absorption response (the absorption onset extended to almost $900 \mathrm{~nm}$ ) than SGT-020 (to $\sim 850 \mathrm{~nm}$ ), which displayed a similar tendency with the absorption spectra on $\mathrm{TiO}_{2}$ film, as shown in Figure S1. On the contrary, the SGT-024-based DSSCs exhibited an extremely low IPCE value (no more than 20\%) from 400 to $900 \mathrm{~nm}$; thus, lower $J_{\text {sc }}$ values were observed. 
(a)

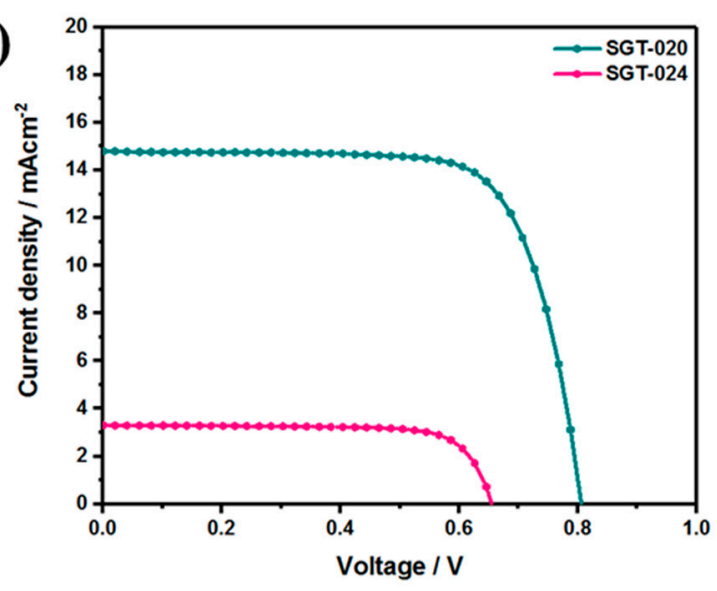

(b)

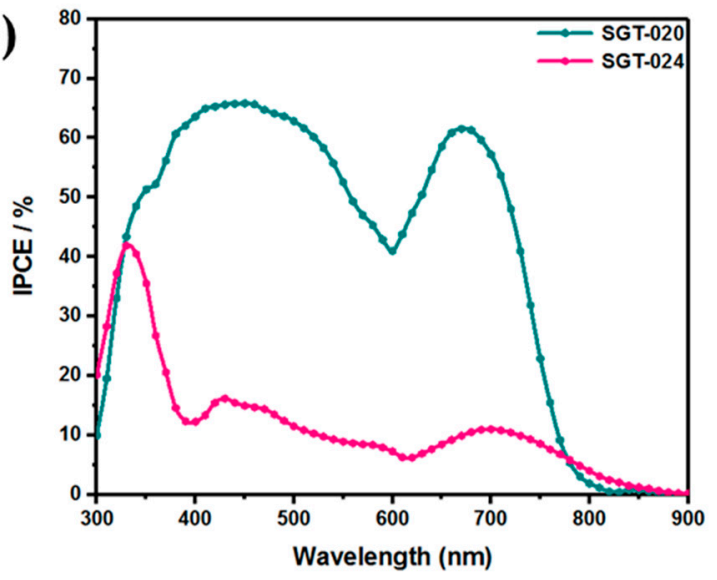

Figure 4. (a) Current-voltage characteristics of the SGT-020 and SGT-024-based DSSCs and (b) the corresponding IPCE spectra under $100 \mathrm{~mW} \mathrm{~cm}^{-2}$ simulated AM 1.5G solar light.

Table 2. Photovoltaic parameters of the SGT-020 and SGT-024-based DSSCs under $100 \mathrm{~mW} \mathrm{~cm}^{-2}$ simulated AM 1.5G solar light.

\begin{tabular}{|c|c|c|c|c|c|c|}
\hline Dye & Co-Adsorbent & $\begin{array}{l}\text { Adsorption Amount } \\
\left(10^{-8} \mathrm{~mol} \mathrm{~cm}^{-2}\right)\end{array}$ & $J_{\mathrm{sc}}\left(\mathrm{mA} \mathrm{cm}^{-2}\right)$ & $V_{o c}(\mathrm{mV})$ & $F F(\%)$ & PCE $^{a}(\%)$ \\
\hline SGT-020 & & 2.13 & $14.8 \pm 0.53$ & $806 \pm 9.8$ & $73.2 \pm 2.4$ & $8.7 \pm 0.25$ \\
\hline SGT-024 & CDC & 1.95 & $3.3 \pm 0.25$ & $655 \pm 7.3$ & $76.3 \pm 1.7$ & $1.7 \pm 0.15$ \\
\hline SGT-020 & & 1.87 & $16.9 \pm 0.32$ & $795 \pm 8.5$ & $76.8 \pm 2.1$ & $10.3 \pm 0.12$ \\
\hline SGT-024 & HC-A1 & 1.79 & $7.3+0.12$ & $724+6.7$ & $79.0+1.8$ & $4.2 \pm 0.19$ \\
\hline
\end{tabular}

In order to further improve the photovoltaic performance of SGT-020 and SGT-024-based DSSCs, another co-adsorbent called HC-A1 was introduced in this study. HC-A1, a multi-functional co-adsorbent widely used in our previous research [13,42], and its structure are shown in Figure S3. As expected, because of the light harvesting in shorter wavelength regions and efficient charge recombination retardation [43-46], the PCE of SGT-020 and SGT-024-based solar cells was dramatically improved to $10.3 \%$ and $4.2 \%$, respectively (see Figure 5). In addition, the dye loading amounts for SGT-020 and SGT-024 were found to be almost no different, implying that the effect of the dye loading amount on photovoltaic performance in this study is relatively small. 


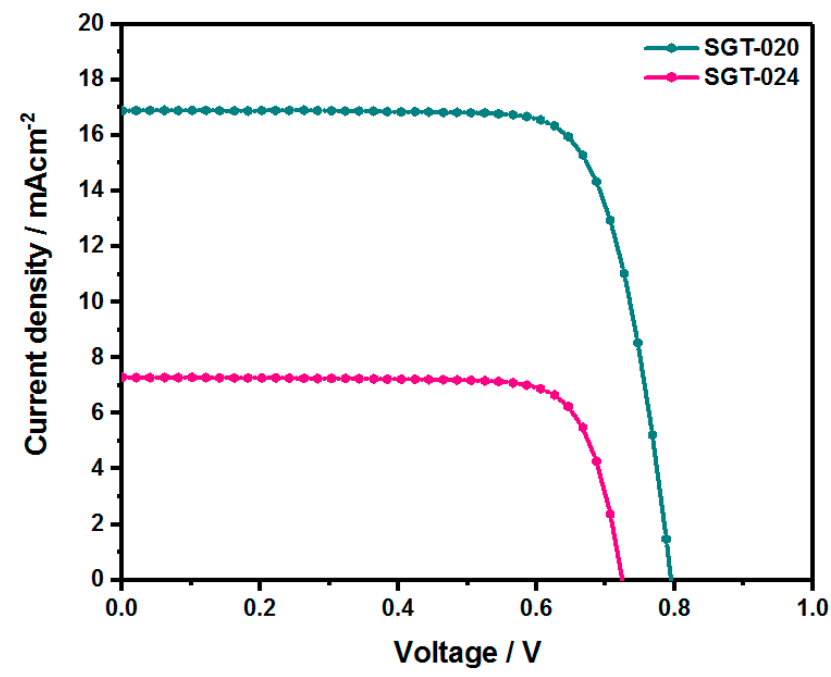

Figure 5. Current-voltage characteristics of the SGT-020 and SGT-024-based DSSCs with HC-A1 under $100 \mathrm{~mW} \mathrm{~cm}^{-2}$ simulated AM 1.5G solar light.

In order to get deeper insight into the photovoltaic performance difference as well as the interfacial charge transfer in all DSSC devices, the electrochemical impedance spectroscopy (EIS) was measured in the dark. Nyquist plots and Bode plots are shown in Figure 6 (a) and (b), respectively, and the EIS data are collected in Table 3. As far as we know, the first, second, and third semicircles correspond to the charge transfer resistance at the counter electrode, the resistance of $\mathrm{TiO}_{2} /$ dye/electrolyte interface, and the diffusion resistance of $\mathrm{Co}(\mathrm{bpy})_{3}{ }^{2+/ 3+}$ redox couple in the electrolyte, respectively. The second semicircle of SGT-024 $\left(R_{r e c}=6.12\right)$ was found to be much smaller than SGT-020 $\left(R_{r e c}=16.8\right)$, indicating that the electron recombination rate of SGT-024 is higher than that of SGT-020. On the other hand, according to the equation $\tau_{\mathrm{r}}=C_{\mu} \cdot R_{\text {rec }}$, the electron lifetime was calculated to be 5.12 or $3.33 \mathrm{~ms}$ for SGT-020 and SGT-024, respectively. Meanwhile, the charge-collection efficiency $\eta_{\mathrm{cc}}$, derived from $\eta_{\mathrm{cc}}=\left(1+R_{\mathrm{tr}} / R_{\mathrm{rec}}\right)^{-1}$ [47], was confirmed to be $84 \%$ for SGT-020 and $68 \%$ for SGT-024. The results obtained above are consistent with the $V_{o c}$ values for the SGT-020-based device $(0.795 \mathrm{~V})$ and SGT-024-based device $(0.724 \mathrm{~V})$. Thus, when compared to SGT-020 and SGT-024, the higher charge recombination rate and the lower charge collection efficiency of the SGT-024-based device may be the main reasons for its disappointing lower photovoltaic performance.
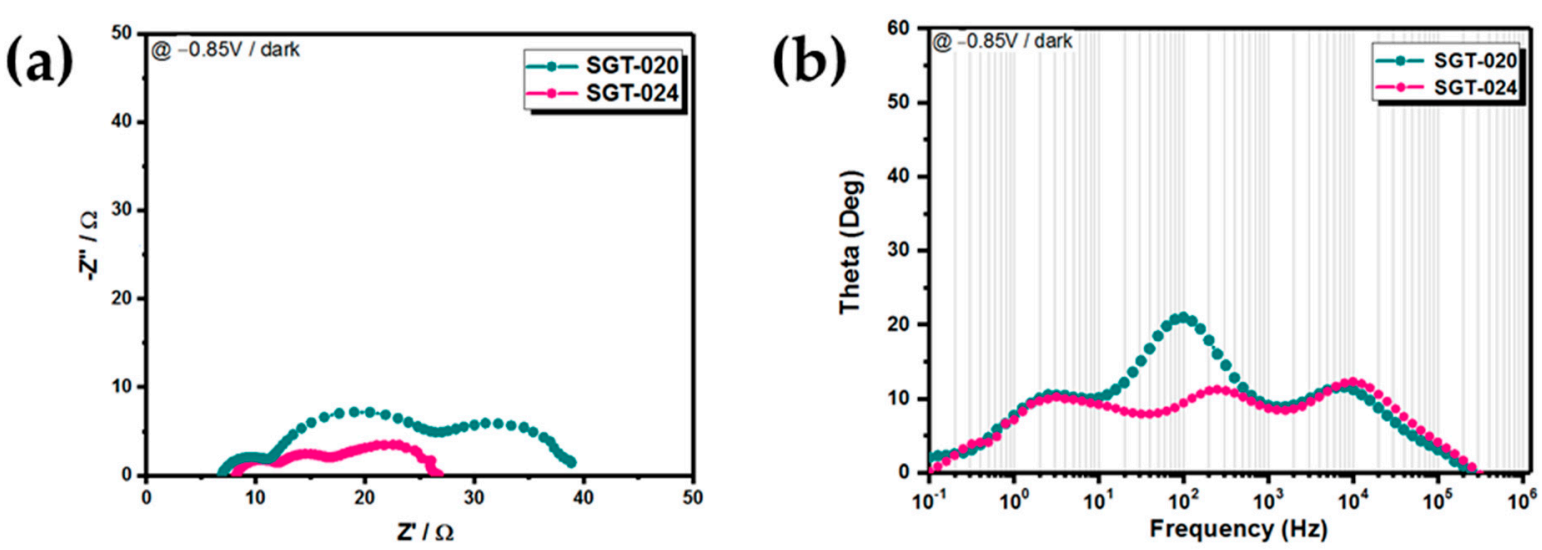

Figure 6. Nyquist plots (a) and Bode phase plots (b) based on SGT-020 and SGT-024 under dark. 
Table 3. EIS data for the SGT-020- and SGT-024-based DSSCs.

\begin{tabular}{ccccccc}
\hline \multirow{2}{*}{ Device $^{\mathbf{a}}$} & \multicolumn{6}{c}{ EIS $^{\mathbf{b}}$} \\
\cline { 2 - 7 } & $\boldsymbol{R}_{\boldsymbol{t r}}(\boldsymbol{\Omega})$ & $\boldsymbol{R}_{\text {rec }}(\boldsymbol{\Omega})$ & $\boldsymbol{C}_{\boldsymbol{\mu}}(\mathbf{m F})$ & $\boldsymbol{\tau}_{\mathbf{n}}(\mathbf{m s})$ & $\boldsymbol{\tau}_{\mathbf{r}}(\mathbf{m s})$ & $\eta_{\boldsymbol{c c}}(\mathbf{\%})$ \\
\hline SGT-020 & 3.27 & 16.8 & 0.30 & 0.99 & 5.12 & 84 \\
SGT-024 & 2.85 & 6.12 & 0.54 & 1.55 & 3.33 & 68 \\
\hline
\end{tabular}

a DSSCs were fabricated with HC-A1. ${ }^{\mathrm{b}}$ forward bias of $0.85 \mathrm{~V}$ under dark conditions. $R_{\mathrm{tr}}$ : transport resistance; $R_{\text {rec }}$ : charge recombination resistance; $C_{\mu}$ : chemical capacitance; $\tau_{\mathrm{n}}$ : transport time; $\tau_{\mathrm{r}}$ : electron lifetime; $\eta_{c c}$ : charge collection efficiency.

\section{Conclusions}

In this work, in order to investigate the structure-performance relationship between the photovoltaic performance and the structure of various acceptors, the pyridothiadiazole group, as a stronger electron-withdrawing group, was incorporated into the well-established skeleton of D-porphyrin-triple bond-acceptor sensitizers by a single atom change for the well-known strong electron-withdrawing benzothiadiazole (BTD) unit. The impact of the pyridothiadiazole group on the optical, electrochemical, and photovoltaic properties of $\mathrm{D}-\pi-\mathrm{A}$ porphyrin sensitizers was investigated by comparing with a benzothiadiazole-substituted SGT-020 porphyrin. The porphyrin SGT-024 presents a red-shifted and broadened Q-band in comparison with SGT-020, which could be attributed to the stronger electron-withdrawing nature of pyridothiadiazole than the BTD unit. This revealed that the introduction of pyridothiadiazole would be an effective strategy for strengthening the absorption of the well-established skeleton of D-porphyrin-triple bond-acceptor sensitizers, although it shows a more moderate PCE of $4.2 \%$ than the DSSC based on SGT-020 (10.3\%). The serious efficiency loss for the SGT-024-based device could be for two main reasons: the fast charge recombination rate caused by the strong electron-withdrawing acceptor, and thus lower charge collection efficiency observed; and the enhanced backbone co-planarity in SGT-024 leading to unexpected dye aggregation. However, the pyridothiadiazole unit is still a promising synthetic strategy to explore $\mathrm{D}-\pi-\mathrm{A}$ structural porphyrins with extended absorption properties. Our study has underlined the importance of a suitable auxiliary acceptor between the dye and the anchoring group for a sensitizer. This should be seriously considered in the further rational design of dye-sensitized solar cells.

Supplementary Materials: The following are available online at http:/ / www.mdpi.com/2079-4991/8/12/1030/ s1. Informative details of material synthesis and characterization, DSSC fabrication, and photoelectrochemical measurements are available in the Supplementary Materials. Figure S1: UV spectra of the porphyrin sensitizers on a $\mathrm{TiO}_{2}$ film $(3 \mu \mathrm{m})$, Figure S2: Cyclic voltammograms of SGT-020 and SGT-024 in THF/ TBAPF 6 and ferrocene external reference, Figure S3: Co-adsorbents used in the dye-sensitized solar cells, Figure S4: ${ }^{1} \mathrm{H}-\mathrm{NMR}$ spectrum $\left(300 \mathrm{MHz},\left(\mathrm{CD}_{3}\right)_{2} \mathrm{CO}\right)$ of SGT-024, Figure S5: ${ }^{13} \mathrm{C}-\mathrm{NMR}$ spectrum $\left(300 \mathrm{MHz},\left(\mathrm{CD}_{3}\right)_{2} \mathrm{CO}\right)$ of SGT-024, Figure S6: Maldi-TOF spectrum of SGT-024, Table S1: Photophysical and electrochemical properties of porphyrin sensitizers by DFT calculations.

Acknowledgments: This work was supported by a Korea University grant.

Conflicts of Interest: The authors declare no conflict of interest.

\section{References}

1. Ji, J.-M.; Zhou, H.; Kim, H.K. Rational design criteria for D- $\pi-A$ structured organic and porphyrin sensitizers for highly efficient dye-sensitized solar cells. J. Mater. Chem. A 2018, 6, 14518-14545. [CrossRef]

2. Hagfeldt, A.; Boschloo, G.; Sun, L.; Kloo, L.; Pettersson, H. Dye-Sensitized Solar Cells. Chem. Rev. 2010, 110, 6595-6663. [CrossRef] [PubMed]

3. Mahmood, A.; Hu, J.-Y.; Xiao, B.; Tang, A.; Wang, X.; Zhou, E. Recent progress in porphyrin-based materials for organic solar cells. J. Mater. Chem. A 2018, 6, 16769-16797. [CrossRef]

4. Yu, R.; Yao, H.; Hou, J. Recent Progress in Ternary Organic Solar Cells Based on Nonfullerene Acceptors. Adv. Energy. Mater. 2018, 8. [CrossRef] 
5. Meng, L.; Zhang, Y.; Wan, X.; Li, C.; Zhang, X.; Wang, Y.; Ke, X.; Xiao, Z.; Ding, L.; Xia, R.; et al. Organic and solution-processed tandem solar cells with $17.3 \%$ efficiency. Science 2018, 361, 1094-1098. [CrossRef] [PubMed]

6. Lu, C.; Choi, I.T.; Kim, J.; Kim, H.K. Simple synthesis and molecular engineering of low-cost and star-shaped carbazole-based hole transporting materials for highly efficient perovskite solar cells. J. Mater. Chem. A 2017, 5, 20263-20276. [CrossRef]

7. Calió, L.; Kazim, S.; Grätzel, M.; Ahmad, S. Hole-Transport Materials for Perovskite Solar Cells. Angezw. Chem. Int. Ed. 2016, 55, 14522-14545. [CrossRef]

8. Yang, S.; Fu, W.; Zhang, Z.; Chen, H.; Li, C.-Z. Recent advances in perovskite solar cells: Efficiency, stability and lead-free perovskite. J. Mater. Chem. A 2017, 5, 11462-11482. [CrossRef]

9. Freitag, M.; Teuscher, J.; Saygili, Y.; Zhang, X.; Giordano, F.; Liska, P.; Hua, J.; Zakeeruddin, S.M.; Moser, J.-E.; Grätzel, M.; et al. Dye-sensitized solar cells for efficient power generation under ambient lighting. Nat. Photonics 2017, 11, 372-378. [CrossRef]

10. Tsai, M.-C.; Wang, C.-L.; Chang, C.-W.; Hsu, C.-W.; Hsiao, Y.-H.; Liu, C.-L.; Wang, C.-C.; Lin, S.-Y.; Lin, C.-Y. A large, ultra-black, efficient and cost-effective dye-sensitized solar module approaching $12 \%$ overall efficiency under 1000 lux indoor light. J. Mater. Chem. A 2018, 6, 1995-2003. [CrossRef]

11. Oregan, B.; Gratzel, M. A Low-Cost, High-Efficiency Solar-Cell Based on Dye-Sensitized Colloidal Tio2 Films. Nature 1991, 353, 737-740. [CrossRef]

12. Kang, S.H.; Choi, I.T.; Kang, M.S.; Eom, Y.K.; Ju, M.J.; Hong, J.Y.; Kang, H.S.; Kim, H.K. Novel D-pi-A structured porphyrin dyes with diphenylamine derived electron-donating substituents for highly efficient dye-sensitized solar cells. J. Mater. Chem. A 2013, 1, 3977-3982. [CrossRef]

13. Eom, Y.K.; Kang, S.H.; Choi, I.T.; Yoo, Y.J.; Kim, J.H.; Kim, H.K. Significant light absorption enhancement by a single heterocyclic unit change in the pi-bridge moiety from thieno[3,2-b]benzothiophene to thieno[3,2-b]indole for high performance dye-sensitized and tandem solar cells. J. Mater. Chem. A 2017, 5, 2297-2308. [CrossRef]

14. Li, P.; Zhang, H.; Troisi, A. Systematic Study of the Effect of Auxiliary Acceptors in D-A' $-\pi-A$ Sensitizers Used on Dye-Sensitized Solar Cells. J. Phys. Chem. C 2018, 122, 23890-23898. [CrossRef]

15. Han, L.; Islam, A.; Chen, H.; Malapaka, C.; Chiranjeevi, B.; Zhang, S.; Yang, X.; Yanagida, M. High-efficiency dye-sensitized solar cell with a novel co-adsorbent. Energy Environ. Sci. 2012, 5. [CrossRef]

16. Kakiage, K.; Aoyama, Y.; Yano, T.; Oya, K.; Fujisawa, J.; Hanaya, M. Highly-efficient dye-sensitized solar cells with collaborative sensitization by silyl-anchor and carboxy-anchor dyes. Chem. Commun. (Camb.) 2015, 51, 15894-15897. [CrossRef] [PubMed]

17. Nazeeruddin, M.K.; Péchy, P.; Grätzel, M. Efficient panchromatic sensitization of nanocrystalline $\mathrm{TiO}_{2}$ films by a black dye based on a trithiocyanato-ruthenium complex. Chem. Commun. 1997, 1705-1706. [CrossRef]

18. Aghazada, S.; Nazeeruddin, M. Ruthenium Complexes as Sensitizers in Dye-Sensitized Solar Cells. Inorganics 2018, 6. [CrossRef]

19. Li, X.; Zhang, X.; Hua, J.; Tian, H. Molecular engineering of organic sensitizers with o,p-dialkoxyphenyl-based bulky donors for highly efficient dye-sensitized solar cells. Mol. Syst. Des. Eng. 2017, 2, 98-122. [CrossRef]

20. Eom, Y.K.; Choi, I.T.; Kang, S.H.; Lee, J.; Kim, J.; Ju, M.J.; Kim, H.K. Thieno[3,2-b][1]benzothiophene Derivative as a New pi-Bridge Unit in D-pi-A Structural Organic Sensitizers with Over $10.47 \%$ Efficiency for Dye-Sensitized Solar Cells. Adv. Energy. Mater. 2015, 5, 1500300. [CrossRef]

21. Higashino, T.; Imahori, H. Porphyrins as excellent dyes for dye-sensitized solar cells: Recent developments and insights. Dalton Trans. 2015, 44, 448-463. [CrossRef] [PubMed]

22. Song, H.; Liu, Q.; Xie, Y. Porphyrin-sensitized solar cells: Systematic molecular optimization, coadsorption and cosensitization. Chem. Commun. 2018, 54, 1811-1824. [CrossRef] [PubMed]

23. Urbani, M.; Gratzel, M.; Nazeeruddin, M.K.; Torres, T. Meso-substituted porphyrins for dye-sensitized solar cells. Chem. Rev. 2014, 114, 12330-12396. [CrossRef] [PubMed]

24. Mathew, S.; Yella, A.; Gao, P.; Humphry-Baker, R.; Curchod, B.F.; Ashari-Astani, N.; Tavernelli, I.; Rothlisberger, U.; Nazeeruddin, M.K.; Gratzel, M. Dye-sensitized solar cells with 13\% efficiency achieved through the molecular engineering of porphyrin sensitizers. Nat. Chem. 2014, 6, 242-247. [CrossRef] [PubMed] 
25. Kang, S.H.; Jeong, M.J.; Eom, Y.K.; Choi, I.T.; Kwon, S.M.; Yoo, Y.; Kim, J.; Kwon, J.; Park, J.H.; Kim, H.K. Porphyrin Sensitizers with Donor Structural Engineering for Superior Performance Dye-Sensitized Solar Cells and Tandem Solar Cells for Water Splitting Applications. Adv. Energy. Mater. 2017, 7, 1602117. [CrossRef]

26. Wang, C.-L.; Hu, J.-Y.; Wu, C.-H.; Kuo, H.-H.; Chang, Y.-C.; Lan, Z.-J.; Wu, H.-P.; Wei-Guang Diau, E.; Lin, C.-Y. Highly efficient porphyrin-sensitized solar cells with enhanced light harvesting ability beyond $800 \mathrm{~nm}$ and efficiency exceeding 10\%. Energy Environ. Sci. 2014, 7. [CrossRef]

27. Chen, Y.; Li, A.; Huang, Z.-H.; Wang, L.-N.; Kang, F. Porphyrin-Based Nanostructures for Photocatalytic Applications. Nanomaterials 2016, 6. [CrossRef] [PubMed]

28. Shiu, J.-W.; Chang, Y.-C.; Chan, C.-Y.; Wu, H.-P.; Hsu, H.-Y.; Wang, C.-L.; Lin, C.-Y.; Diau, E.W.-G. Panchromatic co-sensitization of porphyrin-sensitized solar cells to harvest near-infrared light beyond 900 nm. J. Mater. Chem. A 2015, 3, 1417-1420. [CrossRef]

29. Hill, J.P. Molecular Engineering Combined with Cosensitization Leads to Record Photovoltaic Efficiency for Non-ruthenium Solar Cells. Angew. Chem. Int. Ed. 2016, 55, 2976-2978. [CrossRef] [PubMed]

30. Zhang, L.; Cole, J.M. Dye aggregation in dye-sensitized solar cells. J. Mater. Chem. A 2017, 5, 19541-19559. [CrossRef]

31. Yella, A.; Lee, H.W.; Tsao, H.N.; Yi, C.; Chandiran, A.K.; Nazeeruddin, M.K.; Diau, E.W.; Yeh, C.Y.; Zakeeruddin, S.M.; Gratzel, M. Porphyrin-sensitized solar cells with cobalt (II/III)-based redox electrolyte exceed 12 percent efficiency. Science 2011, 334, 629-634. [CrossRef] [PubMed]

32. Cheng, Y.; Yang, G.; Jiang, H.; Zhao, S.; Liu, Q.; Xie, Y. Organic Sensitizers with Extended Conjugation Frameworks as Cosensitizers of Porphyrins for Developing Efficient Dye-Sensitized Solar Cells. ACS Appl. Mater. Interfaces 2018. [CrossRef] [PubMed]

33. Krishna, J.V.S.; Krishna, N.V.; Chowdhury, T.H.; Singh, S.; Bedja, I.; Islam, A.; Giribabu, L. Kinetics of dye regeneration in liquid electrolyte unveils efficiency of $10.5 \%$ in dye-sensitized solar cells. J. Mater. Chem C 2018, 6, 11444-11456. [CrossRef]

34. Yella, A.; Mai, C.L.; Zakeeruddin, S.M.; Chang, S.N.; Hsieh, C.H.; Yeh, C.Y.; Gratzel, M. Molecular engineering of push-pull porphyrin dyes for highly efficient dye-sensitized solar cells: The role of benzene spacers. Angew. Chem. Int. Ed. Engl. 2014, 53, 2973-2977. [CrossRef] [PubMed]

35. Zhou, H.; Zhang, Y.; Mai, C.-K.; Seifter, J.; Nguyen, T.-Q.; Bazan, G.C.; Heeger, A.J. Solution-Processed pH-Neutral Conjugated Polyelectrolyte Improves Interfacial Contact in Organic Solar Cells. ACS Nano 2014, 9, 371-377. [CrossRef] [PubMed]

36. Liu, X.; Sun, Y.; Hsu, B.B.Y.; Lorbach, A.; Qi, L.; Heeger, A.J.; Bazan, G.C. Design and Properties of Intermediate-Sized Narrow Band-Gap Conjugated Molecules Relevant to Solution-Processed Organic Solar Cells. J. Am. Chem. Soc. 2014, 136, 5697-5708. [CrossRef] [PubMed]

37. Zheng, L.; Cao, Q.; Wang, J.; Chai, Z.; Cai, G.; Ma, Z.; Han, H.; Li, Q.; Li, Z.; Chen, H. Novel D-A- $-\pi-A-T y p e$ Organic Dyes Containing a Ladderlike Dithienocyclopentacarbazole Donor for Effective Dye-Sensitized Solar Cells. ACS Omega 2017, 2, 7048-7056. [CrossRef]

38. Zhang, M.; Yao, Z.; Yan, C.; Cai, Y.; Ren, Y.; Zhang, J.; Wang, P. Unraveling the Pivotal Impacts of Electron-Acceptors on Light Absorption and Carrier Photogeneration in Perylene Dye Sensitized Solar Cells. ACS Photonics 2014, 1, 710-717. [CrossRef]

39. Zhao, Y.; Truhlar, D.G. The M06 suite of density functionals for main group thermochemistry, thermochemical kinetics, noncovalent interactions, excited states, and transition elements: Two new functionals and systematic testing of four M06-class functionals and 12 other functionals. Theor. Chem. Acc. 2007, 120, 215-241. [CrossRef]

40. Hay, P.J.; Wadt, W.R. Ab initio effective core potentials for molecular calculations. Potentials for the transition metal atoms Sc to Hg. J. Chem. Phys. 1985, 82, 270-283. [CrossRef]

41. Hariharan, P.C.; Pople, J.A. The influence of polarization functions on molecular orbital hydrogenation energies. Theor. Chim. Acta 1973, 28, 213-222. [CrossRef]

42. Kang, M.S.; Choi, I.T.; Kim, Y.W.; You, B.S.; Kang, S.H.; Hong, J.Y.; Ju, M.J.; Kim, H.K. Novel D- $-\pi-A$ structured $\mathrm{Zn}$ (ii)-porphyrin dyes with bulky fluorenyl substituted electron donor moieties for dye-sensitized solar cells. J. Mater. Chem. A 2013, 1, 9848. [CrossRef] 
43. Kang, M.S.; Kang, S.H.; Kim, S.G.; Choi, I.T.; Ryu, J.H.; Ju, M.J.; Cho, D.; Lee, J.Y.; Kim, H.K. Novel D- $\pi-A$ structured Zn(ii)-porphyrin dyes containing a bis(3,3-dimethylfluorenyl)amine moiety for dye-sensitised solar cells. Chem. Commun. 2012, 48. [CrossRef] [PubMed]

44. Song, B.J.; Song, H.M.; Choi, I.T.; Kim, S.K.; Seo, K.D.; Kang, M.S.; Lee, M.J.; Cho, D.W.; Ju, M.J.; Kim, H.K. A Desirable Hole-Conducting Coadsorbent for Highly Efficient Dye-Sensitized Solar Cells through an Organic Redox Cascade Strategy. Chem. Eur. J. 2011, 17, 11115-11121. [CrossRef] [PubMed]

45. Lee, M.J.; Seo, K.D.; Song, H.M.; Kang, M.S.; Eom, Y.K.; Kang, H.S.; Kim, H.K. Novel D-pi-A system based on zinc-porphyrin derivatives for highly efficient dye-sensitised solar cells. Tetrahedron Lett. 2011, 52, 3879-3882. [CrossRef]

46. Song, H.M.; Seo, K.D.; Kang, M.S.; Choi, I.T.; Kim, S.K.; Eom, Y.K.; Ryu, J.H.; Ju, M.J.; Kim, H.K. A simple triaryl amine-based dual functioned co-adsorbent for highly efficient dye-sensitized solar cells. J. Mater. Chem. 2012, 22, 3786-3794. [CrossRef]

47. Yum, J.-H.; Baranoff, E.; Kessler, F.; Moehl, T.; Ahmad, S.; Bessho, T.; Marchioro, A.; Ghadiri, E.; Moser, J.-E.; Yi, C.; et al. A cobalt complex redox shuttle for dye-sensitized solar cells with high open-circuit potentials. Nat. Commun. 2012, 3. [CrossRef]

(C) 2018 by the authors. Licensee MDPI, Basel, Switzerland. This article is an open access article distributed under the terms and conditions of the Creative Commons Attribution (CC BY) license (http:/ / creativecommons.org/licenses/by/4.0/). 